\title{
DA FORMAÇÃO SOCIAL EM MARX À FORMAÇÃO SOCIOESPACIAL EM MILTON SANTOS: UMA CATEGORIA GEOGRÁFICA PARA INTERPRETAR O BRASIL?
}

\author{
Thiago Adriano Machado ${ }^{1}$
}

\begin{abstract}
Resumo: O conceito de formação socioespacial foi formulado por Milton Santos na década de 1970 no contexto da chamada renovação crítica da Geografia brasileira, a partir da matriz teórica marxista. Tem por base o conceito marxiano de formação social, ou formação econômica e social, e assimila o debate em torno dele ao integrar a dimensão espacial ao discurso da formação. O objetivo do presente trabalho é analisar a gênese e o desenvolvimento do conceito e discutir sua operacionalidade para uma interpretação da realidade brasileira na obra de Milton Santos. Desse modo, a formação socioespacial dialoga com outros conceitos utilizados pelo autor nos seus estudos sobre o Brasil, tal como território usado e meio geográfico, servindo como uma "teoria das mediações". Para tanto, é posto em relação com o conceito de modo de produção, desdobrando-se em aspectos epistemológicos e metodológicos, tais como: periodização, totalidade, diferenciação espacial, produção e organização do espaço, e relação espaço-tempo.
\end{abstract}

Palavras-chave: Formação socioespacial. Território usado. Brasil. Milton Santos.

\section{FROM SOCIAL FORMATION IN MARX TO SOCIO-SPATIAL FORMATION} IN MILTON SANTOS: DOES IT A GEOGRAPHICAL CATEGORY TO INTERPRET BRAZIL?

Abstract: The concept of socio-spatial formation was formulated by Milton Santos in the 1970s in the context of the so-called critical renewal of Brazilian geography from a Marxist theoretical matrix. It is based on the Marxian concept of social formation, or economic and social formation, and assimilates the debate around it by integrating the spatial dimension into the discourse of formation. The objective of the present work is to analyze the genesis and the development of the concept and to discuss its operability for an interpretation of the Brazilian reality in the work of Milton Santos. In this way, socio-spatial formation dialogues with other concepts used by the author in his studies on Brazil, such as used territory and geographical environment, working as a "theory of mediations". For this, it is related to the concept of mode of production, unfolding in epistemological and methodological aspects, such as: periodization, totality, spatial differentiation, space production and organization, and space-

\footnotetext{
${ }^{1}$ Doutorando do Programa de Pós-Graduação em Geografia da Universidade Federal Fluminense (POSGEO-UFF) e ex-professor substituto da mesma instituição. Contato: machado.ta@gmail.com
} 
time relation.

Keywords: Socio-spatial formation. Used territory. Brazil. Milton Santos.

\section{Introdução}

É recorrente na vida intelectual brasileira a formulação de interpretações acerca da nossa realidade social, tornando-se mesmo uma peculiaridade da nossa vida intelectual esse recorrente pensar sobre nossa formação. Construiu-se, desse modo, uma tradição de estudos que oferece uma diversidade de olhares sobre o País, centrando-se, cada qual, num campo de saber específico, mas que pode ser compreendida sob a alcunha geral de pensamento social brasileiro. Longe de estar restrito às Ciências Sociais (Sociologia, Antropologia e Ciência Política), tal pensamento congrega estudos de corte historiográfico, econômico e literário, mas não tem tido como discurso consolidado aquele de matriz geográfica. Todavia, a ausência de uma obra geográfica celebrada nesse campo maior das interpretações do Brasil não significa que a Geografia tenha abdicado de pensar o País, ou mesmo que não haja estudos orientados segundo uma imaginação geográfica ou espacial. Exemplo disso é a própria obra de Euclides da Cunha, Os sertões, para falarmos de uma perspectiva eminentemente espacial; e a obra de Josué de Castro, A geografia da fome, no sentido de um discurso mais propriamente geográfico sobre o Brasil.

O presente texto tem por objetivo explorar a contribuição geográfica ao estudo da realidade brasileira a partir da obra do geógrafo baiano Milton Santos, centrando-se na sua construção do conceito de formação socioespacial, o qual é tratado pelo autor como uma "teoria das mediações" entre sua teoria social do espaço e o estudo teórico-empírico sobre o Brasil e suas diferenciações espaciais (Santos; Silveira, 2005). Tal formulação conceitual permitiria um diálogo da Geografia com a tradição mais ampla do pensamento social brasileiro ao elevar o conceito de formação à categoria de análise da Geografia, tal como tem sido nas mais diversas interpretações sobre o País. Dentre os trabalhos que se utilizam de tal termo estão clássicos como Formação do Brasil contemporâneo, de Caio Prado Jr.; Formação econômica do Brasil, de Celso Furtado; Formação da literatura brasileira, de Antônio Cândido; Formação histórica do Brasil, de Nelson Werneck Sodré; Casa grande \& senzala: a formação da família brasileira sob o regime da economia patriarcal, de Gilberto Freyre; O povo brasileiro: a formação e o sentido de Brasil, de Darcy Ribeiro; e Os donos do poder: formação do patronato político brasileiro, de Raymundo Faoro.

O recurso à ideia de formação é, portanto, recorrente, ainda que as matrizes teóricas de tais trabalhos sejam diversas (marxista ou weberiana, por exemplo), ou mesmo que os autores não explicitem, como é o caso de Caio Prado Jr., a origem do conceito segundo a formulação da formação social em Marx. Já Milton Santos deixa bem clara a derivação que o conduz da formação econômica e social à formação socioespacial, deixando evidente a matriz marxista em profundo diálogo com o 
discurso geográfico dos anos 1970, renovado a partir da crítica ao neopositivismo da chamada New Geography. A renovação crítica da Geografia empreendida nesse período tem em Milton Santos um membro ativo, e em sua obra Por uma Geografia Nova, de 1978, um marco desse momento de renovação da teoria em Geografia produzida no Brasil. A aproximação com o marxismo e a proposição de uma formação socioespacial estão vinculadas à preocupação em se trabalhar o objeto da Geografia, o espaço geográfico, e a sua definição enquanto "instância social". Tal "instância espacial" ou "geográfica" faria agora parte do processo de totalização histórica, tal qual as instâncias "econômica", "político-jurídica" e "ideológica" (CONTEL, 2014).

O espaço enquanto instância social é contemporâneo à nova apreciação que este conceito passa a ter na teoria social a partir do último quarto do século $\mathrm{XX}$, no que se convencionou chamar de giro espacial. Parte-se, para tanto, de uma crítica à modernidade ao se denunciar que toda ordem de progresso, de revolução e de desenvolvimento estava atrelada à categoria do tempo, ao passo que o espaço seria visto como uma categoria conservadora e estática, reafirmando a assertiva marxiana da aniquilação do espaço pelo tempo. Foucault, em entrevista ao periódico francês Heródote, afirma que "[s]eria necessário fazer uma crítica dessa desqualificação do espaço que vem reinando há várias gerações. Foi com Bergson, ou mesmo antes, que isso começou. $\mathrm{O}$ espaço é o que estava morto, fixo, não dialético, imóvel. Em compensação, o tempo era rico, fecundo, vivo, dialético" (1979, p. 159).

Ocorre, portanto, a passagem de um espaço estático, visto como um palco das ações humanas, para um espaço dialético, produto do trabalho social, o que parece tentar superar a predileção que a Geografia teve, segundo Milton Santos, pela forma em detrimento da formação. "Pode-se dizer que a Geografia se interessou mais pela forma das coisas do que pela sua formação" (SANTOS, 1982a, p. 9). O autor resgata, assim, a discussão entre os conceitos de forma social (conceito estático) e formação social (conceito dinâmico) em Marx, desenvolvida por Emílio Sereni (2013), cujo texto De Marx a Lênin: a categoria de formação econômico-social" é a referência principal de Milton Santos para a formulação de sua formação socioespacial.

Evidencia-se, também, a relação existente entre modo de produção e formação social, de modo que o primeiro seria um conceito abstrato, ao passo que o segundo seria um conceito voltado ao estudo de sociedades concretas, como o foi $O 18$ de Brumário de Luís Bonaparte (2011b), em que Marx trata da França, ou o trabalho de Lênin (1982) O desenvolvimento do capitalismo na Rússia. Duas questões se apresentam, segundo Althusser e Balibar (1970): a primeira decorre da "autonomia relativa" das práticas econômica, política, ideológica e teórica na sociedade, ou seja, a autonomia relativa das distintas instâncias da sociedade; e, segundo, que a cada momento histórico há sempre a convivência e a articulação de distintos modos de produção, ainda que sempre subordinados a um modo de produção hegemônico. 
Com efeito, "[e]lementos residuais de modos passados, as sementes de modos futuros e elementos importados de algum modo existentes contemporaneamente podem todos ser encontrados numa formação social particular" (HARVEY, 2006, p. 26).

O uso dessa matriz teórica para a análise do Brasil foi amplo e animou um acirrado debate sobre a modernização do País. Afinal, a configuração da nossa estrutura agrária, baseada no trabalho escravo e na terra como fonte de riqueza e poder dos seus senhores, abriu margens para interpretações acerca de um passado pré-capitalista com feições feudais. Exemplo disso foram os trabalhos de Alberto Passos Guimarães, Quatro séculos de latifúndios (1963), e de Nelson Werneck Sodré, Formação histórica do Brasil (1962). É exatamente como crítica às interpretações dessa natureza feitas por teóricos do Partido Comunista que Caio Prado Jr. desenvolve, em sua Formação do Brasil contemporâneo, de 1942, a tese do sentido da colonização, refutando a ideia etapista de modos de produção escravista, feudalista, capitalista e socialista na formação brasileira, numa transposição teórica do desenvolvimento capitalista europeu para a nossa realidade periférica.

A expressão de uma formação voltada para fora está presente na diversidade de teorias desenvolvimentistas, como nas teses da CEPAL, aqui representadas por Celso Furtado, mas também no conjunto de teorias da dependência voltadas à crítica ao imperialismo. Os textos de André Gunder Frank, Theotônio dos Santos e Ruy Mauro Marini são exemplos dessa abordagem da dependência baseada na assimetria dos termos de troca como fundamento do nosso papel no sistema-mundo e característica da nossa formação social periférica. Outras compreensões também identificam o vínculo externo oriundo da colonização como origem do nosso subdesenvolvimento, ao exemplo de Fernando Henrique Cardoso, Ignácio Rangel, Florestan Fernandes e João Manuel Cardoso de Mello, dentre outros.

Milton Santos aproximou-se do debate do subdesenvolvimento nesse mesmo período, anos 1960 e 1970, o que se refletiu na temática da urbanização dos países do Terceiro Mundo (SANTOS, 1977b) e na aproximação teórica ao marxismo para tratar do subdesenvolvimento (SANTOS, 1974). O debate sobre a formação socioespacial, desse modo, passa a fornecer subsídios à introdução cada vez mais incisiva dos estudos geográficos na construção de modelos interpretativos do País e em estudos analíticos que se apropriem do sentido da formação, como são os casos de Antônio Carlos Robert de Moraes, Bases da formação territorial do Brasil, de 1999, e Ruy Moreira, Formação espacial brasileira: contribuição crítica aos fundamentos espaciais da Geografia do Brasil, de 2014.

Desta feita, o presente texto busca produzir uma narrativa que parte da gênese do conceito de formação social em Marx, verificando nos seus distintos textos a evolução que tal noção ganhou na obra marxiana. Em seguida, apresentam-se as principais correntes do marxismo que levaram adiante o debate da formação social em conjunto ao de modo de produção, em que pese o marxismo-leninismo e o de viés estruturalista liderado pelo filósofo francês Louis Althusser. Ambas as análises 
são fundamentais para o assunto da seção posterior relativa à formulação do conceito de formação socioespacial na obra de Milton Santos, ressaltando as principais influências do autor e a inserção do conteúdo espacial no conceito em questão. Por fim, a última seção discorre sobre a operacionalidade do conceito de formação socioespacial para uma interpretação geográfica da realidade brasileira a partir da obra miltoniana, de forma a dialogar a formação socioespacial com os demais conceitos que Milton Santos emprega nos seus trabalhos voltados ao estudo do Brasil.

\section{A gênese do conceito de formação social em Marx}

A discussão em torno do conceito de formação social (e seu similar formação econômica e social) tem consolidado a ideia de que ele se refere a sociedades concretas específicas, ao passo que o de modo de produção seria um conceito abstrato. Dessa forma, o modo de produção capitalista estaria, em cada formação social específica, combinado com outros modos de produção subordinados, e esta combinação daria a diferença específica de cada sociedade. Contudo, o desenvolvimento dessa discussão foi bastante nebuloso e confuso no decorrer do século $\mathrm{XX}$, e nos convida a reexaminar os trechos marxianos em que há referência ao conceito de formação social. Küttler (2011) defende que Marx e Engels não teriam desenvolvido o conceito de formação social de maneira sistemática, nem como um conceito histórico fundamental, nem como um modelo de sociedade, posição que contrasta com um dos textos fundamentais do marxismo sobre essa matéria, o de Emílio Sereni, que ressalta o conteúdo histórico da formação social em Marx e promove uma crítica contundente ao modo como os marxistas da II Internacional trataram tal questão.

De certo que no próprio Marx a construção do conceito passa por uma diversidade de termos, cuja coerência passa a ser visualizada somente quando vista no quadro geral da sua obra, e por isso que a relação entre modo de produção e formação social precisa ser colocada no contexto de sua teoria de história, o materialismo histórico. Para tanto, Sereni (2013) parece apontar com sucesso para a ambiguidade dos termos e para o conteúdo eminentemente histórico que guarda a formação social. Küttler (2011) defende que o desenvolvimento de tal conceito em Marx é efeito da dupla revolução burguesa industrial, a inglesa e a francesa, e responderia a tentativas de explicar a estrutura e o desenvolvimento das sociedades já presentes na filosofia clássica alemã (Hegel), na economia política inglesa e na política revolucionária francesa. Goldmann (1967) compreende o papel dessas três sociedades na conformação do racionalismo burguês centrado no individualismo e na quebra dos vínculos com a comunidade, daí que derivam os princípios burgueses da igualdade jurídica, da liberdade e da individualidade. 
Ora, Marx opõe às teses burguesas sua compreensão de que as fundações da história humana se dão na produção e na reprodução das condições materiais de existência. Esse é o ponto de partida para uma teoria do processo histórico das formações (KÜTTLER, 2011). Em A ideologia alemã, de 1846, Marx e Engels apresentam a crítica à filosofia idealista alemã e ao materialismo contemplativo de Feuerbach por meio da sistematização da concepção de materialismo histórico. Ainda que não haja aí a formulação exata do conceito de formação social, o sentido processual se dá na relação entre um conjunto de outros conceitos, tais como o de forma social ou forma da sociedade (Gesellschaftsform), o de forma de intercâmbio (Verkhersform) e o de forma de propriedade, que aparece atrelado ao de modo de produção (Produktionweise).

Marx e Engels (1999) começam com as condições individuais da produção e reprodução dos meios de vida a partir do que se produz e de como se produz, numa primeira acepção da ideia de modo de produção, para logo em seguida inserirem aquela de forma de intercâmbio:

O que os indivíduos são, portanto, depende das condições materiais de produção. Essa produção aparece inicialmente com o aumento da população. Ela própria pressupõe um intercâmbio (Verkehr) dos indivíduos uns com os outros. A forma de intercâmbio é, por sua vez, condicionada pela produção. (MARX E ENGELS, 1999, p. 28) (grifos nossos)

Logo em seguida, a forma de intercâmbio passa a tratar das relações entre nações, da forma como posteriormente a formação social é compreendida. Além disso, apresenta o papel do desenvolvimento das forças produtivas e da divisão do trabalho no processo de formação:

As relações entre umas nações e outras dependem do estado de desenvolvimento em que se encontra cada uma delas no que concerne às forças produtivas, à divisão do trabalho e ao intercâmbio interno. Tal princípio é em geral reconhecido. Entretanto, não apenas a relação de uma nação com outras, mas também toda a estrutura interna desta mesma nação, dependem do grau de desenvolvimento de sua produção e de seu intercâmbio interno e externo. (MARX; ENGELS, 1999, p. 28) (grifos nossos)

O desenvolvimento das forças produtivas, que levam à divisão do trabalho, promove a separação do trabalho industrial e comercial, de um lado, e do trabalho agrícola, de outro, e, com isso, a separação entre campo e cidade, tal como a oposição dos seus interesses. Não seria essa a gênese de uma diferenciação do espaço ou de um desenvolvimento desigual? Não em vão que Milton Santos (1982a) considera a formação econômica e social como uma categoria que diz respeito à "evolução diferencial das sociedades". Contudo, essa dimensão espacial em Marx 
fica restrita às entrelinhas, enquanto o materialismo histórico é compreendido pelas distintas fases da divisão do trabalho, cada nova divisão determinando "igualmente as relações entre os indivíduos entre si, no que se refere ao material, ao instrumento e ao produto do trabalho" (ibidem). Daí decorrem as sucessivas formas de propriedade, iniciando-se pela tribal, seguida pela antiga (estatal/comunal), a feudal (estamental) até chegar à sociedade burguesa (bürgelische Gesellschaft, também entendida como sociedade civil). E a esta, observam Marx e Engels, equivalem às próprias formas de intercâmbio:

A forma de intercâmbio, condicionada pelas forças de produção existentes em todas as fases históricas anteriores e que, por sua vez, as condiciona, é a sociedade civil (...) A sociedade civil abrange todo o intercâmbio material dos indivíduos no interior de uma fase determinada das forças produtivas. Abrange toda a vida comercial e industrial de uma dada fase e, nesse sentido, ultrapassa o Estado e a nação, se bem que, por outro lado, de se fazer valer frente ao exterior como nacionalidade e organizar-se no interior como Estado. (MARX; ENGELS, 1999, p. 52-53) (grifos nossos).

Em resumo, a ação recíproca entre forças produtivas e forma de intercâmbio são o motor histórico das distintas fases das formas de propriedade sucessivas. Organiza-se, assim, não só um processo histórico, mas também geográfico, na conformação da organização política dos Estados nacionais, das relações internaexterna das nações, da separação entre campo e cidade e das condições materiais dispostas na sociedade civil. A recorrência da forma de intercâmbio pode esclarecer o que afirma Sereni (2013) quando ele indica que em $A$ ideologia alemã não haveria ainda um desenvolvimento pleno da noção de relações sociais de produção. Dessa forma, poderíamos atribuir uma equivalência a ambos os conceitos, já que tanto as relações de produção quanto as formas de intercâmbio são apresentadas na obra marxiana em oposição ao desenvolvimento das forças produtivas, oposição esta que levaria às transições de um modo de produção a outro, transformando, assim, progressivamente, a formação social.

$\mathrm{O}$ conceito de forma de sociedade é apresentado em $A$ ideologia alemã em diálogo com o conjunto conceitual anteriormente mencionado. Estabelece uma relação de condicionamento mútuo com o modo de produção, o que indica a necessidade histórica dos homens mudarem continuamente as suas formas de sociedade tradicionais. Volta a ser utilizado por Marx em texto do Grundrisse de 1858 para tratar da sua própria superação (Aufhebung). Ou seja, a ideia de que a forma de sociedade burguesa produz as condições para a sua própria superação a partir daquilo que é o pressuposto de sua reprodução, o desenvolvimento das forças produtivas materiais. 
Tal tendência - que o capital possui, mas que ao mesmo tempo o contradiz como modo de produção limitado e, por isso, o impele à sua própria dissolução - diferencia o capital de todos os modos de produção precedentes e, ao mesmo tempo, contém em si o fato de que o capital é posto como simples ponto de transição. Todas as formas de sociedade anteriores morreram ao desenvolvimento da riqueza - ou, o que é a mesma coisa, do desenvolvimento das forças produtivas sociais. Por essa razão, entre os antigos, que disso tinham consciência, a riqueza era denunciada diretamente como desintegração da comunidade. A constituição feudal, por sua vez, pereceu da indústria urbana, do comércio, da agricultura moderna. (MARX, 2011a, p. 446) (grifos nossos).

Duas noções geográficas chamam atenção nesse trecho do Grundrisse: a primeira, na página anterior, que é a conhecida destruição do espaço pelo tempo dada a necessidade de aceleração do tempo de circulação do capital; e a segunda é a referência à dissolução da vida comunitária - decorrente do desenvolvimento da riqueza. A abordagem que Marx dá a esse tema da supressão da vida comunitária está vinculada à sua reflexão sobre um modo de produção asiático, já que a discussão dos modos de produção relacionados às formas de propriedade apresentadas em $A$ ideologia alemã seriam restritas ao mundo ocidental.

Sereni (2013) destaca a passagem do uso do termo forma social para o de formação social, dado o sentido estático e dinâmico, respectivamente, que cada termo carrega. Talvez por esse sentido estático que tenha havido uma confusão entre modo de produção e forma de sociedade, ou mesmo entre formação social, como denuncia Sereni (2013) em relação aos trabalhos de Plekhanov e Kautsky. O termo formação social (Gesellschaftsformation) é empregado também no Grundrisse, dando relevo à questão da dissolução da vida comunitária pelo avanço da troca, e usa como exemplo concreto a Índia, inserida no que seria o modo de produção asiático:

A troca não começa entre os indivíduos no interior de uma comunidade, mas ali onde as comunidades terminam - em sua fronteira, no ponto de contato entre diferentes comunidades. A propriedade comum foi descoberta recentemente como uma curiosidade própria dos eslavos. Na realidade, entretanto, a Índia oferece-nos um mostruário das mais variadas formas de tal comunidade econômica, mais ou menos em dissolução, mas ainda inteiramente reconhecíveis; e uma investigação histórica mais profunda reencontra tal comunidade como ponto de partida de todos os povos civilizados. O sistema de produção fundado na troca privada é, em primeiro lugar, a dissolução histórica desse comunismo desenvolvido natural e espontaneamente. Contudo, há toda uma série de sistemas econômicos entre o mundo moderno, 
em que o valor de troca domina a produção em toda a sua profundidade e extensão, e as formações sociais cujo fundamento é constituído pela propriedade comunal já dissolvida, sem que [...]. (MARX, 2011a, p. 756-757) (grifos nossos).

No ano seguinte, o mesmo conceito aparece no prefácio à Introdução à contribuição da economia política, mas agora combinado com o de formação econômica e social (ökonomischen Gesellschaftsformation), ressaltando as ideias de ação e de processo como qualificativos da formação. Vê-se, contudo, que aquilo que é permanente em todas essas citações de Marx é o sentido de articulação (Gliederung) do processo de reprodução material da sociedade humana (KÜTTLER, 2011).

Nenhuma formação social jamais desaparece antes que estejam desenvolvidas todas as forças produtivas que possa conter, e as relações de produção novas e superiores não tomam jamais seu lugar antes que as condições materiais de existência dessas relações tenham sido incubadas no próprio seio da velha sociedade. Eis por que a humanidade não se propõe nunca senão os problemas que ela pode resolver, pois, aprofundando a análise, ver-se-á sempre que o próprio problema só se apresenta quando as condições materiais para resolvê-lo existem ou estão em vias de existir. Em grandes traços, podem ser os modos de produção asiático, antigo, feudal e burguês moderno designados como tantas outras épocas progressivas da formação econômica da sociedade. As relações de produção burguesas são a forma antagônica do processo de produção social. Com essa formação social termina, pois, a pré-história da sociedade humana. (MARX, 2008, p. 48) (grifos nossos)

Verificando-se os sentidos aplicados à formação social e à formação econômica da sociedade do trecho acima, é possível concordar com Sereni (2013) quando este autor indica um duplo sentido de tal conceito. Por um lado, a formação social se refere ao processo de formação da sociedade, processo este marcado pela sucessão de modos de produção que permite conceber certa periodização historiográfica. De outro modo, a formação social aparece como resultado de tal processo, como um quadro momentâneo de determinada sociedade. Em termos mais geográficos, poderíamos tratar essa duplicidade de sentidos da mesma maneira que Milton Santos (1996) relaciona os conceitos de totalidade e de totalização.

Os modos de produção como épocas progressivas da formação econômica da sociedade dão relevo aos eventos de transformação social, revoluções ocasionadas pela oposição entre as forças produtivas e as relações sociais, modificando, assim, a formação social específica em questão. Marx volta a utilizar o conceito no prefácio 
de $O$ Capital, em 1867, ao se referir aos capitalistas e proprietários de terra enquanto categorias econômicas:

Meu ponto de vista, que apreende o desenvolvimento da formação econômica da sociedade como um processo históriconatural, pode menos do que qualquer outro responsabilizar o indivíduo por relações das quais ele continua a ser socialmente uma criatura, por mais que, subjetivamente, ele possa se colocar acima delas. (MARX, 2013, p. 80) (grifos nossos).

Tal como o texto acima acentua, o sentido processual da formação social é o de mais destaque, e este é reforçado em cartas que Marx escreve para a revolucionária russa Vera Zasulich, datadas de 1881, quando ao comentar sobre as comunidades de aldeias russas reitera a existência de épocas sucessivas e "séries ascendentes" (SERENI, 2013). Do mesmo modo que no trecho de O Capital Marx compara essas fases da formação social às épocas sucessivas das formações geológicas - analogia que remete à formação social como um "processo histórico-natural". No início do capítulo V, quando trata do processo de trabalho (trabalho, objeto do trabalho e meios de trabalho), volta a citar a formação econômica da sociedade em comparação com processos de evolução da natureza:

A mesma importância que as relíquias de ossos têm para o conhecimento da organização das espécies de animais extintas têm também as relíquias de meios de trabalho para a compreensão de formações socioeconomicas extintas. O que diferencia as épocas econômicas não é "o que" é produzido, mas "como", "com que meios de trabalho". (MARX, 2013, p. 257) (grifos nossos).

John Bellamy Forster (2011) mostra bem como Marx acompanhava de perto os trabalhos desenvolvidos nas ciências naturais, especialmente o de Darwin, e que o recurso a analogias com conceitos dessas ciências lhe era comum. O uso do termo metabolismo [Stoffwechsel], para tratar das relações entre o homem e a natureza mediadas pelo processo de trabalho, foi tomado de empréstimo do químico alemão Justus Von Liebig. Uma tradição de estudos tem abordado a dimensão ecológica em Marx (SCHMIDT, 1977; O’CONNOR, 1988; BURKETT, 1999; FORSTER, 2011), influenciando, inclusive, a Geografia, como é o caso do conceito de estrutura ecológico-territorial (QUAINI, 1979).

O trabalho é, antes de tudo, um processo entre o homem e a natureza, processo este em que o homem, por sua própria ação, medeia, regula e controla seu metabolismo com a natureza. Ele se confronta com a matéria natural como com uma potência natural [Naturmacht]. A fim de se apropriar da matéria natural de uma forma útil para sua própria vida, ele põe em movimento as forças 
naturais pertencentes à sua corporeidade: seus braços e pernas, cabeça e mãos. Agindo sobre a natureza externa e modificando-a por meio desse movimento, ele modifica, ao mesmo tempo, sua própria natureza. (MARX, 2013, p. 255) (grifos nossos).

O estudo da natureza é para Marx algo muito além de uma simples produção de analogias, está na base do processo de trabalho e no centro da sua dimensão ontológica, e é fundamental para o entendimento da relação entre a produção do espaço e sua diferenciação. Desse modo, é compreensível que Marx trace um paralelo entre as formações sociais e as formações geológicas por ter tido contato, segundo Forster (2011), tanto com a geologia histórica quanto com a Geografia histórica de Carl Ritter, um dos pais da Geografia moderna. Na geologia histórica a referência fundamental é de Abraham Gottlob Werner, criador da geognose, teoria que afirmava que as diferenças essenciais entre as rochas de vários tipos se encontravam no seu "modo e formação", sendo as formações geológicas definidas como entidades históricas, singulares, não como tipos naturais.

O desenvolvimento teórico do conceito da formação social em Marx centra-se, portanto, numa perspectiva histórica, em que os atributos espaciais de uma sociedade concreta, territorialmente delimitada, são, ainda que presentes, majoritariamente subentendidos. No O 18 de Brumário de Luís Bonaparte, de 1852, Marx aplica o materialismo histórico à realidade concreta da França pósrevolucionária e ratifica a formação social como um conceito estreitamente atrelado à sua teoria revolucionária. Mesmo que citando o termo formação social apenas uma única vez, a perspectiva progressiva das formações sociais está presente no corpo de sua análise e é bem retratada no célebre trecho:

Os homens fazem a sua própria história; contudo, não a fazem de livre e espontânea vontade, pois não são eles quem escolhem as circunstâncias sob as quais ela é feita, mas estas lhe foram transmitidas assim como se encontram. A tradição de todas as gerações passadas é como um pesadelo que comprime o cérebro dos vivos. E justamente quando parecem estar empenhados em transformar a si mesmos e as coisas, em criar algo nunca antes visto, exatamente nessas épocas de crise revolucionária, eles conjuram temerosamente a ajuda dos espíritos do passado, tomam emprestados os seus nomes, as suas palavras de ordem, o seu figurino, a fim de representar, com essa venerável roupagem tradicional e essa linguagem tomada de empréstimo, as novas cenas da história mundial. (MARX, 2011b, p. 25-26).

Em resumo, Küttler (2011) apresenta a formação social em Marx, numa perspectiva genética, nos seguintes pontos: 
- Formação progressiva por meio de tentativa contínua de assegurar as necessidades básicas de existência.

- Associação com a teoria da sucessão de formações, pensando a transição do capitalismo para o socialismo.

- Formação social como objeto de estudo da ciência histórica em oposição à filosofia histórica especulativa.

\section{O debate do modo de produção e da formação social no marxismo}

O debate acerca da relação entre modo de produção e formação social tomou o corpo que tem hoje depois do desenvolvimento ocorrido no seio do marxismoleninismo e do marxismo estruturalista althusseriano. Duas obras marcam o resgate que Lênin promove da formação econômico-social, como ele prefere, elevando tal conceito a um papel central no materialismo histórico. Em Quem são os amigos do povo?, redigido em 1894, Lênin tenta restaurar o conceito diante das simplificações promovidas pelos marxistas da II Internacional, com a exceção de Antonio Labriola e Franz Mehring. As críticas recaíam sobre Plekhanov e Kautsky, que reduziam e confundiam o conceito de formação social com o de modo de produção, ou mesmo o ignoravam. Em Lênin, ao contrário, a formação social ganha o status de categoria principal do materialismo histórico por representar a unidade das diferentes esferas da vida em sociedade: econômica, política, social e cultural; e por expressar tal unidade na continuidade e na descontinuidade do processo histórico.

A noção de unidade em Lênin, mas também presente em Labriola, coaduna com aquela de ação recíproca que Engels defende como relação entre base e superestrutura, de modo que as distintas instâncias sociais formem, por meio da formação social, uma totalidade (SERENI, 2013). Essa ideia de totalidade que a formação social expressa seria importante naquele momento para corrigir as simplificações e deformações, sobretudo de viés positivista, da teoria de história em Marx. Entendida em termos do materialismo histórico, a totalidade pode ser descrita na forma apresentada por Karel Kosik (1976):

Totalidade significa: realidade como um todo estruturado, dialético, no qual um fato qualquer (classes de fatos, conjunto de fatos) pode vir a ser racionalmente compreendido (...) [A] realidade é entendida como concreticidade, como um todo que possui a sua própria estrutura (e que, portanto, não é caótico), que se desenvolve (e, portanto, não é imutável nem dado uma vez por todas), que se vai criando (e que, portanto, não é um todo perfeito e acabado no seu conjunto e não é mutável apenas em suas partes isoladas, mas na maneira de ordená-las). (KOSIK, 1976, p. 44).

É mirando a formação social como totalidade que Cesare Luporini propõe, segundo Sereni (2013), um modelo metodológico da formação econômico-social, e 
toma como referência o estudo de Lênin sobre $O$ desenvolvimento do capitalismo na Rússia, de 1899, considerando-o uma "magistral aplicação interpretativa" (Sereni, 2013, p. 330). Com tal intuito, se deveria combinar uma perspectiva sistemáticaestrutural, que abarcasse o sistema de estruturas necessárias, com uma perspectiva histórica, ao considerar a gênese, o desenvolvimento e a destruição da própria estrutura dada, nos moldes da totalidade concreta de que nos fala Karel Kosik.

Contudo, essa dupla visão da formação social, tanto sistemática-estrutural quanto histórica, parece condizer com a problematização empreendida por Althusser e Balibar (1970) acerca de uma ambiguidade do conceito, ora empírico, designando o objeto de uma análise concreta, ora abstrato, "substituindo a noção ideológica de 'sociedade' e designando o objeto da ciência da história, na medida em que essa é uma totalidade de instâncias articuladas sobre as bases de um determinado modo de produção" (ALTHUSSER E BALIBAR, 1970, p. 207). Os autores defendem que tal ambiguidade deve ser a fonte da confusão na literatura marxista entre o conceito de formação social e sua infraestrutura econômica, ou modo de produção, e completam que muitos estudos voltados aos modos de produção não capitalista ou précapitalista testemunham isso.

Esse é de fato um debate muito espinhoso, e vimos na seção anterior que Marx não o deixa suficientemente delimitado. O seu desenvolvimento é por vezes confuso, dada a profusão de termos variados que em décadas de trabalho são utilizados para dar conta de sua preocupação teórica, mas é na esteira dos avanços empreendidos por Lênin e pela análise estrutural de Althusser que a narrativa consolidada da formação social é sistematizada em Althusser e Balibar (1970, p. 203-204):

- A relação entre formação social e modo de produção ocorre no nível das contradições entre classes sociais (1) e no nível das contradições entre as forças produtivas e as relações de produção (2).

- A sucessão de épocas históricas, conformadas pelas transformações nas formações sociais e transição de modos de produção, refere-se ao princípio da periodização.

- Articulação dos diferentes níveis (instâncias sociais ou práticas sociais) que conformam a formação social: base econômica, superestrutura legal ou política e formas de consciência social.

Maurice Godelier (1971) começa o seu texto sobre a formação social com uma definição bem delimitada: "O conceito de formação social é mais útil na análise de realidades particulares, concretas e históricas capturadas no tempo irreversível, real, de dados períodos históricos" (GODELIER, 1971, p. 63). Em seguida elenca um conjunto de passos científicos para uma definição sintética a partir do ponto de vista marxista:

- Identificar o número e as características dos vários modos de produção 
que se combinam de modo particular numa sociedade específica e constituem sua base econômica num período específico.

- Identificar os vários elementos da superestrutura social e ideológica cujas origem e função correspondem a vários modos de produção.

- Definir a exata forma e o conteúdo da articulação e da combinação dos vários modos de produção numa ordem hierárquica, na medida em que um modo de produção domina os outros e de certo modo sujeita-os às necessidades e lógica de seu próprio modo de funcionamento, e integraos, mais ou menos, ao mecanismo de sua própria reprodução.

- Definir as distintas funções de cada elemento da superestrutura e da ideologia, que, a despeito de serem originados em diferentes modos de produção, se combinam de modo específico, correspondendo à ordem hierárquica dos elementos. Não importa suas origens, tais elementos superestruturais são assim redefinidos e geram um novo conteúdo.

Já Nico Poulantzas (1976), em As classes sociais no capitalismo contemporâneo, traçou um estudo das metrópoles imperialistas e suas relações com as formações sociais dominadas e dependentes, o qual merece nota por tentar produzir uma análise concreta das formações sociais no capitalismo monopolista e por aliar a esta análise um conceito caro à Geografia que é aquele de desenvolvimento desigual.

A cadeia imperialista está, por sua vez, marcada pelo desenvolvimento desigual; esta cadeia reflete em cada elo uma especificidade de cada formação social. Esta especificidade depende das formas que revestem o predomínio do modo de produção capitalista na escala internacional sobre todos os outros modos e formas de produção no seio de cada formação social. Em efeito, a reprodução do modo de produção capitalista em sua dupla tendência atesta que ele não pode existir senão submetendo os demais modos e formas de produção, e apropriando-se de seus elementos (força de trabalho, meios de trabalho). É a articulação, em sua reprodução, do modo de produção capitalista e dos modos e formas de produção em formações sociais o que produz o desenvolvimento desigual. (POULANTZAS, 1976, p. 39).

Samir Amin (1976) também conjuga o estudo das formações sociais periféricas ao desenvolvimento desigual, correlação esta expressa no título de Desenvolvimento desigual: um ensaio sobre as formações sociais do capitalismo periférico. Outros trabalhos se voltam para a discussão que atrela modos de produção a formações sociais periféricas, como o de Ernest Laclau (1971), Feudalismo e capitalismo na América Latina, que analisa as teses de ocorrência de feudalismo ou capitalismo comercial na fase colonial da América Latina por meio, sobretudo, da crítica ao trabalho de André Gunder Frank, O desenvolvimento do subdesenvolvimento (1966).

Para fechar um quadro geral, porém limitado, dessa discussão sobre a formação social no marxismo não se pode abrir mão do conjunto de autores que orbitavam em 
torno da revista italiana Crítica Marxista e que posteriormente foram publicados no Cuadernos Pasado y Presente n. 39 (1973), na Argentina. São eles Valentino Gerratana (1972), que publicou Formazione Sociale e Societá di Transizione; Cesare Luporini (1966), Realità e Storicità: Economia e Dialetica nel Marxismo; e Emílio Sereni (1970), dentre outros, aqui citado em tradução para o português (2013) do Da Marx a Lenin: la categoria di'formazione economico-sociale. Todos estes são referências recorrentes nos principais textos de Milton Santos sobre a formação social e socioespacial.

\section{Geografia e marxismo em Milton Santos: o conceito de formação socioespacial}

"O ato de produzir é igualmente o ato de produzir espaço" (SANTOS, 2002, p. 202). Com essa afirmação Milton Santos demarca a sua Geografia sob a influência do materialismo histórico e da dialética marxista, pensando o espaço como um produto do trabalho humano e partindo para uma análise do espaço humano para além dos reducionismos positivistas e da mera descrição. Ainda assim, ele não renuncia a um certo ecletismo que lhe é característico (CONTEL, 2014), o que o permite transitar entre autores de diversas filiações teóricas, tal como Sartre, Simmel, Durkheim, Weber e Lefebvre. Como afirmara em entrevista pouco antes de falecer, Milton Santos preferia pensar em si não como um marxista, mas sim como um marxizante, o que ganha sentido na sua repulsa aos jargões e às citações fora de contexto, assim como o reconhecimento de que devemos desenvolver uma teoria maior que a dos nossos mestres, para que eles não sejam inúteis (SANTOS, 1974).

É com esse compromisso que ele se apropria da discussão de modo de produção e de formação social para inserir o espaço como instância fundamental da realidade e daí pensar a formação socioespacial. Tal formulação coincide com o seu período de exílio, durante o qual lecionou em diversas universidades da Europa, da América do Norte, da África e da América Latina, tendo contato com realidades concretas tão distintas, e em especial com o fenômeno do subdesenvolvimento. Nesse período, participa da coordenação de um número especial da Antipode, revista de Geografia radical norte-americana, e também contribui com o periódico francês de Geografia marxista, Heródote. É no volume IX da Antipode, de 1977, sob sua coordenação e a de Richard Peet, que Milton Santos publica seu trabalho seminal "Sociedade e espaço: formação social como teoria e método", no qual propõe o conceito de formação socioespacial.

Publicou ainda no mesmo periódico os artigos: "Geografia, marxismo e subdesenvolvimento" (1974); "Dialética espacial: os dois circuitos da economia urbana em países subdesenvolvidos" (1977b); "Planejando o subdesenvolvimento" (1977c); e "A totalidade do diabo: como as formas espaciais difundem o capital e mudam a estrutura social" (1980). Todos eles combinando a compreensão 
geográfica da realidade do subdesenvolvimento com o materialismo histórico. Não é, portanto, contraditório ser a formação social a categoria marxiana utilizada como centro teórico da sua abordagem "marxizante" nesse período, pois é exatamente aquela afeita ao estudo das sociedades concretas. Auxilia, também, no avanço teórico sobre o espaço, superando a dualidade homem-natureza ao pensá-la como sinônimo de espaço, na medida em que se considere a natureza transformada, uma segunda natureza, como a chamou Marx.

Embebido na literatura marxista sobre o tema, em especial os italianos da Crítica Marxista, Milton Santos mira a formação econômica e social por sua capacidade de permitir o conhecimento de uma sociedade na sua totalidade e suas frações, tal como as similaridades entre distintas formações e a especificidade de cada uma, naquilo que a distingue das outras. A noção de totalidade é muito importante por vir acompanhada da totalização, o que remete ao duplo sentido da formação social em Sereni (2013), quais sejam: a formação social como processo e a formação social como produto, totalização e totalidade, respectivamente. Ou, no mesmo sentido, primeira e segunda natureza, em Marx; natura naturans e natura naturata, em Spinoza; e potência e ato, em Aristóteles (SANTOS, 1996). No último caso, potência e ato servindo de referenciais para a distinção entre modo de produção e formação social:

Aqui, a distinção entre modo de produção e formação social aparece como necessidade metodológica. $\mathrm{O}$ modo de produção seria o "gênero" cujas formações sociais seriam as "espécies"; o modo de produção seria apenas uma possibilidade de realização e somente a formação econômica e social seria a possibilidade realizada. (SANTOS, 1982a, p. 13).

Outro aspecto dessa dialética espacial é aquele entre produção e organização. O valor das formas espaciais sendo dado pelo modo de produção, que qualifica a produção do espaço; ao passo que a formação social se organiza no arranjo espacial do todo e das partes, ou seja, na organização do espaço:

A diferença entre os lugares são o resultado do arranjo espacial dos modos de produção particulares. O "valor" de cada local depende de níveis qualitativos e quantitativos dos modos de produção e da maneira como eles se combinam. Assim a organização local da sociedade e do espaço reproduz a ordem internacional (SANTOS, 1974, p. 8). Os modos de produção tornam-se concretos sobre uma base territorial historicamente determinada. Deste ponto de vista, as formas espaciais seriam uma linguagem dos modos de produção. Daí, na sua determinação geográfica, serem eles seletivos, reforçando dessa maneira a especificidade dos lugares. (SANTOS, 1982a, p. 14) 
Esquema da relação entre a formação econômica e social e a formação socioespacial

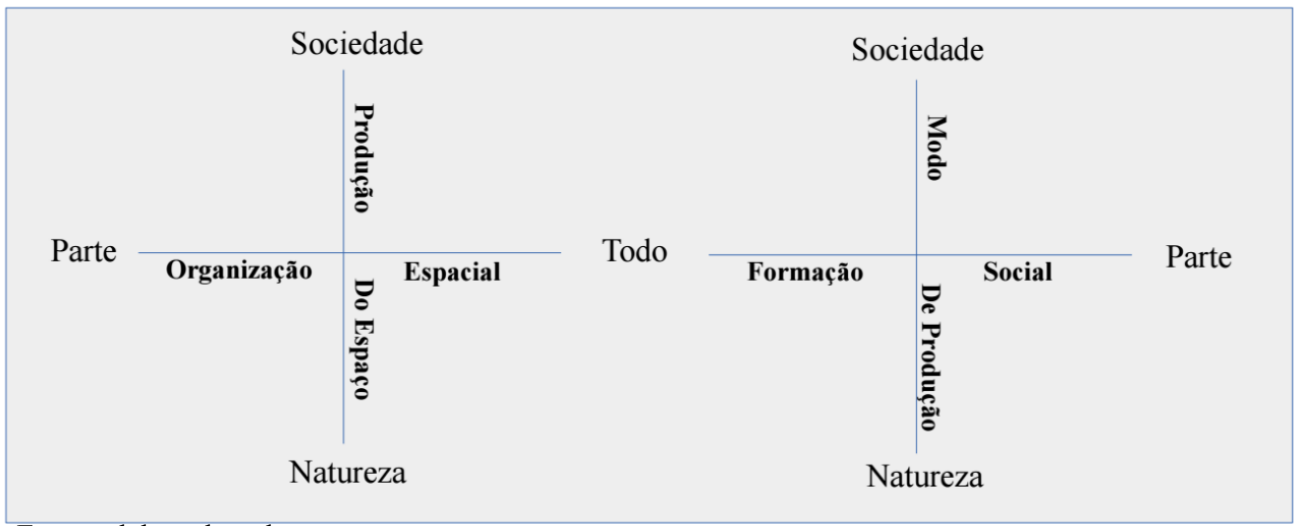

Fonte: elaborado pelo autor.

A esta relação entre produção e organização do espaço soma-se aquela do tempo e do espaço em respeito ao modo de produção e à formação social, segundo a abordagem das fases progressivas da formação econômica e social - de forma que "[o]s modos de produção inscrevem a história no tempo, as formações sociais escrevem-na no espaço" (Santos, 1982a, p. 15). Como o espaço não pode agora ser apartado do tempo, a formação social não pode ser compreendida sem os modos de produção. O trabalho, a práxis humana, anima, assim, a dialética entre modo de produção e formação social, de produção e de organização do espaço, e do espaço e do tempo. A forma espacial é o que permite a concreticidade dessas relações ao empiricizar o tempo, e o arranjo espacial é uma combinação de formas espaciais tributárias de modos de produção diferentes e, portanto, de tempos distintos.

Tomada individualmente, cada forma geográfica é representativa de um modo de produção ou de um dos seus momentos. A história dos modos de produção é também, e sob este aspecto preciso, a história da sucessão das formas criadas a seu serviço. A história da formação social é aquela da superposição de formas criadas pela sucessão de modos de produção, da sua complexificação sobre seu "território espacial" (...). (SANTOS, 1982a, p. 15).

Essa capacidade da forma de "informar" o tempo traz ao debate algumas questões levantadas por Milton Santos, tal como a de tempo espacial, mas, sobretudo, a de rugosidades. Ao tomar esse conceito de empréstimo da geomorfologia, similar ao que Marx fez quando produziu a analogia entre as formações sociais e as formações geológicas, Milton Santos recorre a Sartre para compreender a materialidade como 
uma contrafinalidade que exerce sobre os homens e a história uma ação passiva, uma práxis roubada. O espaço é um testemunho de momentos de um modo de produção cuja memória está inscrita na paisagem fixada. Guarda nas suas formas modos de produção pretéritos, com determinado processo de trabalho, meios de produção, técnicas específicas. As rugosidades nos indicariam, assim, o produto momentâneo de determinada formação espacial:

As rugosidades são o espaço construído, o tempo histórico que se transformou em paisagem, incorporado ao espaço. As rugosidades nos oferecem, mesmo sem tradução imediata, restos de uma divisão de trabalho internacional, manifestada localmente por combinações particulares do capital, das técnicas e dos trabalhos utilizados. Assim, o espaço, espaço-paisagem, é o testemunho de um momento do modo de produção nestas suas manifestações concretas, o testemunho de um momento do mundo. (SANTOS, 2002, p. 173).

Dessa totalidade socioespacial Milton Santos trabalha com quatro conceitos que norteiam suas análises: forma, função, estrutura e processo. $\mathrm{O}$ processo representando o transcurso temporal que conforma a formação; a estrutura espacial como uma estrutura complexa, composta por elementos não homólogos, de classes distintas; e as formas, combinadas com as funções, expressando-se como formasconteúdo. $\mathrm{O}$ espaço é, portanto, um todo estrutural que possui uma gênese e um desenvolvimento, uma formação, e que é conformado por um arranjo espacial de formas-conteúdo.

Considerado esse quadro do espaço como uma totalidade, a passagem efetiva da formação social ou da formação social e econômica para a formação socioespacial se realiza com o reconhecimento do espaço como uma das esferas da vida de que falava Lênin, elemento da unidade entre base econômica e superestrutura. Com tal intuito Milton Santos (2002) propõe em Por uma Geografia Nova a compreensão do espaço enquanto fato social, fator e instância social. A noção de fato é explorada a partir da definição de Durkheim: "todo meio de ação [ou meio de existência], fixo ou não, capaz de exercer sobre o indivíduo uma coação externa (...) todo meio de ação aparece como geral em relação a uma sociedade determinada e que, ao mesmo tempo, existe por si mesmo independentemente das formas individuais de sua manifestação?" (apud SANTOS, 2002, p. 160).

Ora, essa coação externa promovida pelo espaço sobre o indivíduo não seria a contrafinalidade do espaço, aquela ação passiva de que fala Sartre? Em termos marxistas, o espaço como fato deveria cumprir a sua dupla função: a de revelar a si e ao todo de que faz parte (KOSIK, 1976). Muito se pode saber de uma sociedade pelo seu espaço, pela forma como ele é produzido e pela forma como ele é organizado, as relações que ele contém e em que ele é contido, as memórias que ele preserva e guarda, as resistências que ele imprime na ação humana enquanto ambiente construído. 
Tais resistências impostas pelo ambiente construído o transformam num fator. A circulação de capital demanda uma infraestrutura espacial, os sistemas de engenharia, para que o processo de acumulação ocorra do modo mais eficiente. Mas esse mesmo espaço construído pode, posteriormente, mostrar-se uma barreira ao novo desenvolvimento das forças produtivas num momento técnico distinto. As rugosidades transformam-se em empecilho, e mais uma vez, como diz Marx (2011a, p. 445), o espaço tem que ser destruído pelo tempo para se encurtar o tempo de giro do capital por meio da ampliação dos fluxos.

Por fim, o espaço é uma instância social, aos modos de quando David Harvey e Manuel Castells consideram o sistema urbano como uma "estrutura social" (SANTOS, 2002). Inserido no todo das instâncias sociais (econômica, jurídicopolítica; ideológico-cultural) o espaço está submetido à lei da totalidade, goza de relativa autonomia, e, tal qual as outras estruturas sociais, é uma estrutura subordinada-subordinante. "Isso nos obriga a um outro exercício metodológico e teórico fundamental, o de apontar qual o lugar real que tem o espaço humano na sociedade global, ou, ainda melhor, na formação econômica e social" (SANTOS, 2002, p. 180). Esse lugar do espaço é o do reconhecimento de um espaço dinâmico, dialético, em movimento, algo que na década de 1970, como todas as inovações teóricas da influência do materialismo histórico na Geografia, parecia ser um reconhecimento tardio.

Como pudemos esquecer por tanto tempo esta inseparabilidade das realidades e das noções de sociedade e de espaço inerentes à categoria de formação social? Só o atraso teórico conhecido por essas duas noções pode explicar que não se tenha procurado reuni-las num conceito único. Não se pode falar de uma lei separada da evolução das formações espaciais. De fato, é de formações socioespaciais que se trata. (SANTOS, 1982a, p. 19)

Milton Santos fala como se essa inseparabilidade estivesse sempre lá, no mundo real e concreto em que a concreticidade do espaço e do tempo só nos permitisse falar de um materialismo histórico e geográfico. Armen Mamigonian (1996) defende que o artigo de Milton Santos "Sociedade e espaço - a formação social como teoria e método" é um marco fundamental da renovação marxista da Geografia Humana, e traça um paralelo entre o desenvolvimento do marxismo e da Geografia na Alemanha do século XIX a partir do tronco comum da Filosofia clássica alemã (Kant e Hegel). Daí as noções de totalidade e dialética compartilhadas por ambas áreas do conhecimento, aqui a dialética marxista e seu materialismo histórico, ali os holismos de Humboldt e de Ritter em suas geografias das plantas e da região, respectivamente.

A conciliação do marxismo com a Geografia seria registrada, assim, por essa 
formulação da formação socioespacial? Não sem antes enfrentar os embates que ocorrem no século XX por movimentos ora mais enfáticos, ora mais tímidos, como por exemplo a Geografia Ativa dos anos 1950, que orbitava em torno, sobretudo, de Pierre George. Outros nomes como Karl Wittfogel na Alemanha e Massimo Quaini na Itália ampliaram as filiações marxistas na Geografia, mas, a partir das décadas de 1960 e 1970, consolidou-se uma Geografia crítica ou radical, a qual teve no Brasil o nome de Milton Santos como referência, tal como seu livro Por uma Geografia Nova como obra fundamental. Outros textos geográficos que ficaram consagrados nesse momento da renovação crítica também lançaram mão do conceito de formação socioespacial, como foi o caso de Ruy Moreira, com o "A Geografia serve para desvendar máscaras sociais" (1982), no qual o autor ressaltou a importância da reprodução das relações de classe para uma reprodução da própria formação espacial.

Coloca-se, aqui, a questão das articulações das instâncias de uma formação econômico-social e desta com a formação espacial em termos de totalidade. Dependendo da posição em que os homens se coloquem face aos meios de produção, as relações de produção serão relações sociais entre iguais ou entre proprietários e não proprietários, surgindo, neste segundo caso, uma estrutura social de classes sociais que comandará o processo global da formação econômico-social. Assim, numa formação econômico-social desse tipo, toda vez que no processo de reprodução se reproduzirem as relações de produção, estará na verdade com a reprodução destas se reproduzindo a estrutura de classes. (MOREIRA, 1982, p. 47).

Ruy Moreira (2016) retornou a esse tema recentemente e reitera o corte territorial do Estado como marco da formação espacial e a sua relação com as instâncias econômicas, políticas e culturais. Além disso, ressaltou o papel das tensões na formação espacial a partir da centralização do Estado e das contradições da estrutura econômica da sociedade burguesa, sem esquecer, todavia, as tensões oriundas do avanço sobre formações espaciais extracapitalistas - mantendo o seu referencial em Rosa Luxemburgo, expresso nos confrontos de espaço e contraespaço em face das tentativas de dissolução da vida comunitária.

Uma ampla diversidade de outros autores trabalhou com o conceito de formação socioespacial ou utilizou a formulação miltoniana como suporte para as suas pesquisas empíricas, contudo o esforço que Milton Santos empreendeu em cooperação com María Laura Silveira para produzir uma obra de fôlego sobre o Brasil pode nos dar indicativos mais sólidos do lugar desse conceito na obra desse autor. 


\section{A formação socioespacial como teoria das mediações: operacionalização para o estudo do Brasil}

Tal qual no debate marxista da formação econômica e social, a formação socioespacial tem como unidade geográfica o Estado nacional (Santos, 1982b). Armar-se com o ferramental epistemológico da formação socioespacial só tem sentido e, portanto, pressupõe um projeto de análise de alguma realidade concreta nacional. Duas obras de Milton Santos deixam isso mais explícito: $O$ Brasil: território e sociedade no início do século $X X$, de 2001, em coautoria com María Laura Silveira, e A urbanização brasileira, publicado em 1993.

$\mathrm{Na}$ realidade, há muito tempo que desejo empreender dois estudos de síntese, um mais alentado, sobre a evolução do território brasileiro (sobretudo em sua fase mais recente) e outro, mais sintético, sobre a urbanização. Este, de fato, seria a retomada de um artigo publicado, nos anos de 1960, nos Annales de Géographie, sobre a urbanização brasileira. (SANTOS, 2013 [1993], p. 16).

Um discurso sobre o Brasil não é, portanto, algo acidental na obra miltoniana, mas um projeto que acompanha o seu desenvolvimento teórico-metodológico, tanto é assim que o autor propõe como eixo estruturante de sua metodologia geográfica uma periodização fundamentada nos meios geográficos, os quais teriam como critério-base o fenômeno técnico a partir de seus sucessivos sistemas técnicos. Assim, Milton Santos compreende o território brasileiro segundo o meio natural, os distintos meios técnicos, e o meio técnico-científico-informacional, que confere ao Brasil o status de espaço nacional da economia internacional.

Desse modo, pode-se traçar o caminho teórico-metodológico que permitiu o recurso ao conceito de território usado no seu discurso sobre Brasil como forma de operacionalizar a "grande teoria" (teoria social do espaço/território) com a "pequena teoria" (estudo teórico-empírico sobre o Brasil e suas diferenciações espaciais) por meio de uma "teoria das mediações", a formação socioespacial. Uma formação socioespacial do território brasileiro compreendida a partir da sucessão e da convivência dos distintos meios geográficos. Por isso, compreender o País em Milton Santos é começar pelo fim, pelo livro O Brasil: território e sociedade no início do século XXI, no qual o autor - em parceria com Maria Laura Silveira elabora uma narrativa ao mesmo tempo sintética e analítica da realidade brasileira. Todavia, a categoria aqui central não é a de formação socioespacial, mas a de território:

A busca de uma periodização do território brasileiro é um partido 
essencial para um projeto ambicioso: fazer falar o território. Assim como a economia foi considerada como a fala privilegiada da nação por Celso Furtado, o povo por Darcy Ribeiro e a cultura por Florestan Fernandes, pretendemos considerar o território como a fala privilegiada da nação. (SANTOS; SILVEIRA, 2005, p. 27) (grifos meus).

Esse trecho não apenas coloca o território como o conceito central desse projeto de compreender a nação, mas ressalta a abordagem espaçotemporal na obra de Milton Santos, um traço teórico-metodológico que faz o seu espaço geográfico e o seu território usado serem conceitos relacionais, como também explicita o seu interesse de construir uma abordagem geográfica do País que possa dialogar com outras "falas" anteriormente privilegiadas e consagradas do pensamento social brasileiro. Mas fazer falar o território impõe a questão de qual território se está falando. E aqui os autores fazem a distinção entre o território em si, o espaço político de uma nação, e o território usado, no particípio que evoca a noção de totalidade, ou em uso, para dar o tom do processo de totalização, de movimento. O território usado é outro modo de dizer espaço geográfico.

Nota-se que, tal qual a formação socioespacial, o território usado é visto como uma totalidade e como um processo de totalização e possui equivalência com o conceito de espaço geográfico. Isso pode ser melhor compreendido quando María Laura Silveira (2014) reconhece a intercambialidade entre categorias correspondentes, "o que conduz a pensar a formação socioespacial como sinônimo de espaço geográfico, território usado, meio geográfico e espaço banal" (Silveira, 2014, p. 143). De certo que os conceitos são relacionais e que suas intercambialidades indiquem para a existência de um sistema teórico orgânico, contudo, o artifício de transformá-los em sinônimos corre o risco da vulgarização dos conceitos - algo que vitimou a relação entre modo de produção e formação social - e que tem causado certa polêmica com a própria utilização do conceito de território usado (Moraes, 2013).

A perda do protagonismo da formação socioespacial a desloca para uma mediação entre a teoria e a empiria, consolidando um papel eminentemente metodológico para essa categoria. Segundo Silveira (2011), é a formação socioespacial que formula os critérios das seleções de fatos e teorias, ainda que as evidências desse uso do conceito não saltem aos olhos no corpo do texto.

Nessa direção, outro esforço do livro foi o de sugerir uma teoria das mediações, base para a escolha de fatos e relações relevantes. Daí a utilização da categoria de formação socioespacial. Assim, a escala de análise utilizada que, para algumas perspectivas, pode parecer demasiadamente ambiciosa e resultar na impossibilidade de trabalhar com o País como totalidade é, na realidade, uma das chaves do método. A formação socioespacial é a totalidade que explica os processos, daí que a escala que ela representa, mais do 
que uma delimitação, é um imprescindível partido de método. Como é uma mediação entre as possibilidades dos períodos históricos e a existência nos lugares, permitir-nos-ia transformar um discurso geral sobre o presente numa análise concreta de um país e suas regiões sem, por isso, cair numa mera descrição dos lugares a modo de inventário. (SILVEIRA, 2011, p. 157).

De todo modo, Santos e Silveira (2005) estabelecem um sistema teórico coerente e que dialoga com a constelação de conceitos marxistas dos modos de produção, das instâncias sociais e da oposição entre o nível das forças produtivas e as relações de produção, por meio da relação entre formação socioespacial e meio geográfico. Definido a partir da intensidade do fenômeno técnico, o meio geográfico permite uma periodização das continuidades e descontinuidades da formação socioespacial: meio natural, sucessivos meios técnicos e meio técnico-científico-informacional estabelecendo-se como "épocas progressivas" da formação socioespacial. A divisão do trabalho, expressa territorialmente, conduz à diferenciação espacial dos subsistemas do espaço nacional (SANTOS, 1982b) e conforma o arranjo espacial de forma concreta segundo a realidade urbano-regional. Por fim, a formação socioespacial não pode ignorar os circuitos espaciais de produção e os círculos de cooperação, como bem lembra María Laura Silveira (2014).

\section{Esquema do sistema teórico em Santos e Silveira (2005)}

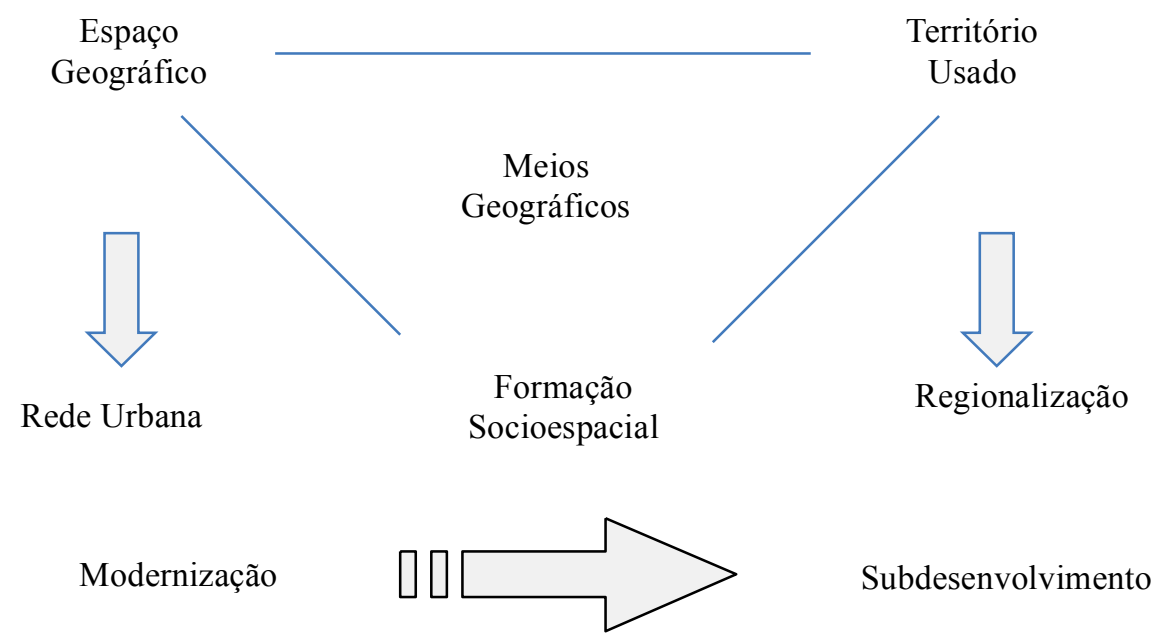

Fonte: elaborado pelo autor. 
Pode-se, desse modo, estruturar os principais conceitos para uma abordagem geográfica do Brasil na obra de Milton Santos a partir da análise do processo de modernização do País. Modernização esta submetida às forças externas e caracterizada por um descompasso entre o processo de industrialização e a integração do território nacional, o que corresponde a uma rede urbana e uma rede de transporte que se estruturam de modo tardio (Santos, 2004). As disparidades regionais e as características próprias da urbanização brasileira explicitam o modo geográfico dessa modernização seletiva que faz do Brasil um "espaço periférico".

A história da formação dessa periferia é sintetizada aqui por meio dos sucessivos meios geográficos e se expressa mais contemporaneamente pela alta seletividade do meio técnico-científico-informacional. O território é normado pelos fluxos verticalizados do capital financeiro e pelo incremento dos objetos técnicos, fixos, que compõem os sistemas de engenharia (SANTOS; SILVEIRA, 2005). O espaço brasileiro é produzido e o seu território usado segundo os artifícios seletivos da informação e do dinheiro. E essa produção, ou este uso, leva à diferenciação espacial que configura $O s$ quatro Brasis, ou seja, aquela regionalização do território nacional centrada na região concentrada - organizada em torno da metrópole de São Paulo, e que dialoga com a periodização da rede urbana nacional.

A formação socioespacial como teoria das mediações não reduz o potencial dessa categoria, mas, ao contrário, o amplifica por respeitar o sentido dinâmico, processual e dialético que esse termo carrega. A formação, desse modo, medeia os atributos espaciais entre a paisagem, o arranjo das formas geográficas e dos objetos espaciais, e o ordenamento territorial, expressão política do espaço. A formação medeia as estruturas espaciais e as escalas geográficas; carrega consigo o sentido de inércia dinâmica e, por fim, consolida-se como categoria da economia política do espaço no período da globalização. Em tempos que se anunciam como descontinuidade no âmbito político do País, a formação socioespacial deve ter muito a nos dizer, pois é o espaço que carrega a memória de onde viemos e a inércia dinâmica do nosso vir a ser enquanto sociedade.

\section{Considerações finais}

A pergunta referente à formação socioespacial ser uma categoria geográfica para se produzir uma interpretação do Brasil abre muitas questões a serem exploradas. $\mathrm{Na}$ verdade, há aí toda uma agenda de pesquisa referente à relação entre a Geografia e o pensamento social brasileiro, para a qual o trabalho de Milton Santos pode ser um norte devido ao seu papel na formulação de uma teoria geográfica pensada desde o Terceiro Mundo. Contudo, a lacuna temporal na utilização de tal conceito pelo autor que o formulou indica que o seu desenvolvimento teórico pode não ter avançado suficientemente, dado que depois do final da década de 1970 a formação socioespacial tenha aparecido de maneira tímida nos seus textos. Ela retorna de maneira contundente apenas no livro sobre o Brasil no início do século XXI, mas, 
ainda que exerça um papel metodológico aparentemente fundamental, é muito pouco nomeada, dando lugar ao conceito de território usado como o portador da primazia de um discurso geográfico do Brasil.

Contudo, a análise aqui empreendida permite identificar avanços significativos a partir da construção teórica centrada na formação socioespacial. Primeiramente, ela promove uma integração do tempo e do espaço, aproximando-se de uma perspectiva relacional. Milton Santos consegue com sucesso inserir na Geografia um debate em que, se o espaço não havia sido ignorado, era no mínimo subentendido, não havendo, até então, uma narrativa explícita que conferisse às formações sociais uma base espacial de maneira estruturada. A formação socioespacial permite pensar o materialismo histórico como materialismo histórico e geográfico.

Decorre daí a importância da relação entre os conceitos de formação socioespacial, modo de produção e meio geográfico. O modo de produção compreendido na empiricização do tempo por meio das formas espaciais constituindo as chamadas rugosidades e dando qualidade diferencial ao espaço. Contudo, os modos de produção passam a ter expressão geográfica a partir dos meios geográficos, definidos segundo os conteúdos técnicos que caracterizam cada época não pelo o que se produz, mas pelo como se produz. Os sucessivos meios geográficos indicando, assim, os respectivos modos de produção do espaço social, e são as transições de um meio geográfico a outro as descontinuidades que modificam o conteúdo da formação socioespacial.

Outro aspecto a ser ressaltado é de cunho metodológico, já que a formação socioespacial como "teoria das mediações" permite a produção de periodizações do território e, ao ser entendida como uma totalidade, a compreensão do território como condição e produto da atividade social. Além do mais, o estudo das partes e do todo da totalidade é o fundamento da análise urbano-regional imprescindível à compreensão da modernização seletiva do território brasileiro por meio dos circuitos espaciais de produção e dos círculos de cooperação.

Por fim, a análise geográfica do Brasil em Milton Santos pode ser situada numa certa tradição crítica de interpretação do Brasil, na qual podemos incluir Caio Prado Jr., Celso Furtado e Florestan Fernandes, apenas para dar alguns exemplos. Não apenas por ter se apropriado da matriz marxista, mas, sobretudo, por ter formulado uma teoria geográfica voltada à realidade brasileira e latino-americana. $\mathrm{O}$ conceito de formação socioespacial é fundamental nesse empreendimento e, se sua operacionalização não foi esgotada na obra de Milton Santos, ostenta ainda múltiplas possibilidades analíticas a serem exploradas. Abre-se, assim, uma agenda de pesquisa em que investigações relativas à relação entre Estado e sociedade civil, às relações étnico-raciais e à constituição das classes sociais no Brasil possam ser realizadas a partir da formação socioespacial. 


\section{Referências}

ALTHUSSER, L.; BALIBAR, E. (1970) Reading Capital. London: NLB. AMIN, S. (1976). Unequal Development: an essay on social formations in peripheral capitalism. Sussex: The Havester Press.

BURKETT, P. (1999) Marx and Nature: a red and green perspective. New York: St. Martin's Press.

CARAVAGLIA, J. C. (1978) Um modo de produção subsidiário: a organização econômica das comunidades guaranizadas durante os séculos XVII-XVIII na formação regional Alto Peruano-Rio Platense. In: GENRAM, F. (Coord.). Conceito de Modo de Produção. Rio de Janeiro: Paz \& Terra.

CONTEL, F. B. (2014) Milton Santos. In: PERICÁS, L. B.; SECCO, L. F. (Orgs.) Intérpretes do Brasil: clássicos, rebeldes e renegados. São Paulo: Boitempo.

FORSTER, J. B. (2011) A ecologia de Marx: materialismo e natureza. Rio de Janeiro: Civilização Brasileira.

FOUCAULT, M. (1979) Sobre a Geografia. In: Metafisica do poder. Org. Roberto Machado. Rio de Janeiro: Edições Graal.

FRANK, A. G. (1966) The Development of Underdevelopment. New York: Monthly Review. FURTADO, C. (2007) Formação Econômica do Brasil. São Paulo: Companhia das Letras. GERRATANA, V. (1972) Formazione Sociale e Societá di Transizione. Crítica Marxista, vol. 10, n. 1.

GODELIER, M. (1971) Qu'est ce que definir une "formation economique et sociale". L'exemple des Icas. La Pensee, n. 159.

GOLDMANN, L. (1967) Origem da dialética: a comunidade humana e o universo em Kant. Rio de Janeiro: Paz e Terra.

GUIMARÃES, A.P. (1963) Quatro séculos de latifúndios. São Paulo: Fulgor.

HARVEY, D. (2006) The Limits to Capital. New York: Verso.

KÜTTLER, W. (2011) Social Formation. Historical Materialism, vol. 19, n. 4.

KOSIK, K. (1976) A Dialética do Concreto. Rio de Janeiro: Paz \& Terra.

LACLAU, E. (1971) Feudalism and Capitalism in Latin America. New Left Review 1/67.

LÊNIN, V. (1982) O desenvolvimento do capitalismo na Rússia. São Paulo: Abril Cultural.

LUPORINI, C. (1966) Realità e Storicità: Economia e Dialetica nel Marxismo. Crítica Marxista, vol. 4, n. 1.

MAMIGONIAN, A. (1996) A Geografia e "a formação social como teoria e método. In: SOUZA, M. A. A. (Org.) O mundo do cidadão, um cidadão do mundo. São Paulo: Hucitec.

MARX, K. (2013) O Capital: crítica da economía política. Livro I. São Paulo: 
Boitempo.

. (2011a) Grudrisse: manuscritos econômicos de 1857-1858. Esboços da crítica da economia política. São Paulo: Boitempo.

. (2011b) O 18 de Brumário de Luís Bonaparte. São Paulo: Boitempo.

. (2008) Contribuição à crítica da economia política. São Paulo: Expressão

Popular.

MARX, K.; ENGELS, F. (1999) A ideologia alemã (Feuerbach). São Paulo: Hucitec.

MORAES, A. C. R. (2013) Território na Geografia de Milton Santos. São Paulo: Anna Blume.

. (1999) Bases da formação territorial do Brasil. São Paulo: Hucitec.

MOREIRA, R. (2016) A Geografia do espaço-mundo: conflitos e superações no espaço do capital. Rio de Janeiro: Consequência.

. (2014) A formação espacial brasileira: contribuição crítica aos fundamentos espaciais da Geografia do Brasil. Rio de Janeiro: Consequência.

. (1982) A Geografia serve para desvendar máscaras sociais. In: MOREIRA, R. (Org.). Geografia: teoria e crítica. O saber posto em questão. Petrópolis: Vozes.

O'CONNOR, J. (1988) Capitalism, Nature, Socialism: a theoretical introduction. In: Capitalism, Nature, Socialism, n. 1, vol. 1.

POULANTZAS, N. (1976) Las clases sociales en el capitalismo actual. México: Siglo XXI.

PRADO JR., C. (2011) Formação do Brasil contemporâneo: colônia. São Paulo: Companhia das Letras.

QUAINI, M. (1979) Geografia e marxismo. São Paulo: Paz \& Terra.

SANTOS, M. (2013) A urbanização brasileira. São Paulo: Edusp.

. (2004). O espaço dividido: os dois circuitos da economia urbana dos países subdesenvolvidos. São Paulo: Edusp.

. (2002) Por uma Geografia Nova. São Paulo: Edusp.

Hucitec.

. (1996) A natureza do espaço. Técnica, tempo. Razão, emoção. São Paulo:

. (1987) Espaço do cidadão. São Paulo: Nobel.

. (1985) Espaço e método. São Paulo: Nobel.

. (1982a) Sociedade e espaço: a formação social como teoria e como método In: SANTOS, M. Espaço e sociedade. Petrópolis: Vozes.

. (1982b) O Estado-nação como espaço, totalidade e método. In: SANTOS, M. Espaço e sociedade. Petrópolis: Vozes.

. (1980) The Devil's totality: how geographical forms diffuse capital and 
change social structure. Antipode, vol. XII, n. 3.

. (1977a) Society and Space: the social formation as theory and method. Antipode, vol. IX, n. 1.

. (1977b) The spatial dialects: the two circuits of urban economy in underdeveloped countries. Antipode, vol. IX, n. 3.

. (1977c) Planning Underdevelopment. Antipode, vol. IX, n. 3.

. (1974) Geography, Marxism and Underdevelopment. Antipode, vol. VI, n. 3.

SANTOS, M.; SILVEIRA, M. L. (2005). O Brasil: território e sociedade no início do século XXI. Rio de Janeiro e São Paulo: Record.

SCHMIDT, A. (1977) El concepto de naturaleza en Marx. Madrid: Siglo XXI Editores.

SERENI, E. (2013) De Marx a Lênin: a categoria de formação econômico-social. Meridiano, n. 2.

SILVEIRA, M. L. (2014). Geografía y formación socioespacial: por un debate sustantivo. Estudios Socioterritoriales, n. 16, vol. 2.

. (2011) O Brasil: território e sociedade no início do século XXI - a história de um livro. ACTA Geográfica, Edição especial "Cidades na Amazônia Brasileira". SODRÉ, N. W. (1962) Formação histórica do Brasil. São Paulo: Brasiliense.

Data de submissão: 07/07/2016.

Data de aceite: 22/12/2016. 